\title{
Endometrial inflammatory markers of the early immune response in mares susceptible or resistant to persistent breeding-induced endometritis
}

\author{
E M Woodward, M Christoffersen ${ }^{1}$, J Campos, A Betancourt, D Horohov, K E Scoggin, \\ E L Squires and M H T Troedsson
}

Department of Veterinary Science, The Maxwell H. Gluck Equine Research Center, University of Kentucky, Lexington, Kentucky 40546-0099, USA and ${ }^{1}$ Department of Large Animal Sciences, Veterinary Reproduction and Obstetrics, University of Copenhagen, Dyrlaegevej 68, DK-1870 Frederiksberg C, Denmark

Correspondence should be addressed to E M Woodward; Email: elizabeth.woodward@uky.edu

\begin{abstract}
Transient endometritis after breeding is necessary for clearance of bacteria and spermatozoa; however, in a subpopulation of mares, the inflammation fails to resolve in a timely fashion. The objective of this study was to describe the uterine inflammatory response in mares susceptible or resistant to persistent breeding-induced endometritis (PBIE) during the first $\mathbf{2 4} \mathrm{h}$ after induction of uterine inflammation. Twelve mares were classified as susceptible $(n=6)$ or resistant $(n=6)$ to PBIE. Mares were inseminated over five estrous cycles and endometrial biopsies were collected at one time point per cycle before (0) and 2, 6, 12, and $24 \mathrm{~h}$ after insemination. qPCR analysis for IL1B, IL6, IL8, IFNG, TNF (TNFA), IL10, and IL1RN was performed, and endometrial inflammatory cells were counted for each sample. Relative quantification values reported fold changes in mRNA expression from $0 \mathrm{~h}$ values. A general pattern of expression post insemination was observed in both groups of mares. Cytokine mRNA increased at $2 \mathrm{~h}$, peaked between 2 and $12 \mathrm{~h}$, and then decreased. Differences were detected between groups of mares $6 \mathrm{~h}$ after challenge; resistant mares had higher mRNA expression of IL6, IL1RN, and IL10 than susceptible mares. Susceptible mares had an increased number of polymorphonuclear neutrophils in the endometrium 2 and $12 \mathrm{~h}$ after breeding when compared with resistant mares. These findings describe an inherent difference in the initial immune response to insemination and may help explain the transient nature of inflammation in resistant mares, whereas susceptible mares develop a persistent inflammation.

Reproduction (2013) 145 289-296
\end{abstract}

\section{Introduction}

A transient uterine inflammation in response to breeding (semen and contaminating bacteria) is a normal physiological reaction that aids in the clearance of excess semen and debris from the uterus. The conceptus arrives into the uterus around 5.5-6.5 days after fertilization (Oguri \& Tsutsumi 1972, Betteridge et al. 1982, Freeman et al. 1991), and in horses and other species, uterine inflammation was found to be harmful to the conceptus and interfere with pregnancy (Adams et al. 1987, Reilas et al. 2000, Hill \& Gilbert 2008). Therefore, it is important that breeding-induced endometritis be resolved before the arrival of the conceptus into the uterus. While uterine inflammation normally resolves within 24-48 h, some mares develop a persistent endometritis, which has been cited as a leading reproductive health concern in equine veterinary practice (Traub-Dargatz et al. 1991). Susceptibility to the failure of uterine clearance of a bacterial challenge has been associated with impaired myoelectrical activity in response to inflammation (Troedsson et al. 1993a); however, the underlying mechanisms responsible remain poorly understood.

The inflammatory process involves chemokineinitiated recruitment of polymorphonuclear neutrophils (PMNs) and other inflammatory cells to the area of insult, leading to the removal of pathogens and resolution of inflammation (Parham 2005). Understanding the mechanisms of uterine inflammation is important when developing new protocols and treatments for persistent breeding-induced endometritis (PBIE). Fumuso et al. investigated endometrial cytokine mRNA expression $24 \mathrm{~h}$ after artificial insemination in susceptible and resistant mares. The group detected an increase in the pro-inflammatory cytokines interleukin-1 $\beta$ (IL1B), IL6, and tumor necrosis factor $\alpha(T N F(T N F A))$ in all mares after insemination and found that mares susceptible to PBIE had higher basal levels of mRNA expression of the cytokines when compared with resistant mares 
(Fumuso et al. 2003). The same group subsequently found increased mRNA expression of the neutrophil chemoattractant IL8 and lower expression of the inflammatory modulating cytokine IL 10 in susceptible mares compared with resistant mares $24 \mathrm{~h}$ after insemination (Fumuso et al. 2006, 2007). However, in contrast to Fumuso et al. other researchers were unable to find a significant IL8 response $24 \mathrm{~h}$ after insemination in reproductively normal pony mares (Nash et al. 2010). Endometrial mRNA expression of TNFA, IL1B, IL8, and IL10 were found to be upregulated in response to an i.u. infusion with a high dose of Escherichia coli as early as $3 \mathrm{~h}$ after challenge in normal diestrous mares (Christoffersen et al. 2010). Uterine clearance begins as early as $30 \mathrm{~min}$ after infusion with radiocolloid (LeBlanc et al. 1994), and myoelectrical patterns in susceptible and resistant mares differ as early as $6 \mathrm{~h}$ after bacterial inoculation into the uterus (Troedsson et al. 1993a). Given these findings, it is possible that the critical time frame for cytokine mRNA expression as it relates to susceptibility to PBIE occurs much earlier than $24 \mathrm{~h}$ (as previously investigated). Knowledge of the time frame of events and inflammatory cascades after breeding is critical for understanding of the development of PBIE. Therefore, the objective of this study was to profile pro- and anti-inflammatory cytokine mRNA expression patterns and the numbers of endometrial $\mathrm{PMNs}$ in the equine endometrium at several time points within the first $24 \mathrm{~h}$ after a spermatozoa challenge. We hypothesized that i) there is a change in the endometrial inflammatory cytokine mRNA expression and endometrial PMN infiltration in mares at varying time points up to $24 \mathrm{~h}$ after insemination and ii) that mares susceptible to PBIE have a different profile of cytokine expression and endometrial PMN infiltration than mares resistant to PBIE within the first $24 \mathrm{~h}$ of breeding.

\section{Results}

\section{Cytokine mRNA expression}

ILIB mRNA expression was increased at 2 and $6 \mathrm{~h}$ for both groups of mares after insemination $(P \leq 0.01)$. No differences were observed between susceptible and resistant mares at any time point (Fig. 1a).

IL6 mRNA expression was increased at all time points in both groups of mares after insemination $(P \leq 0.047)$. In addition, susceptible mares had a higher level of
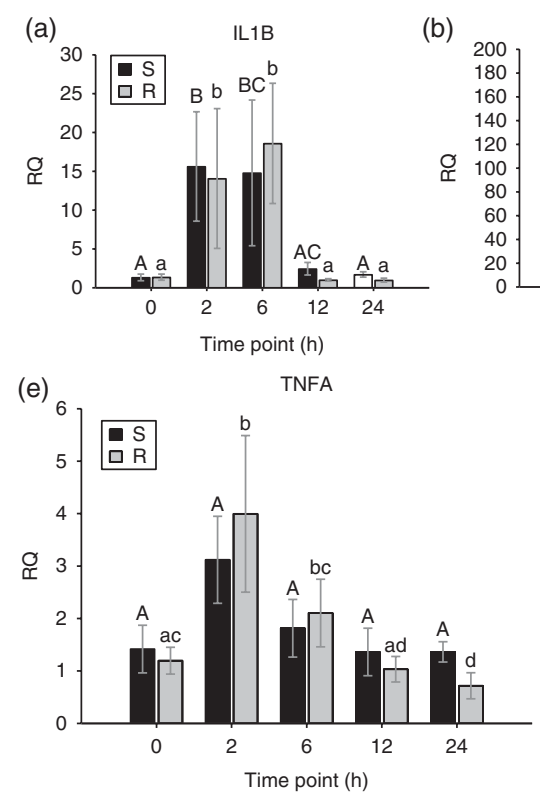

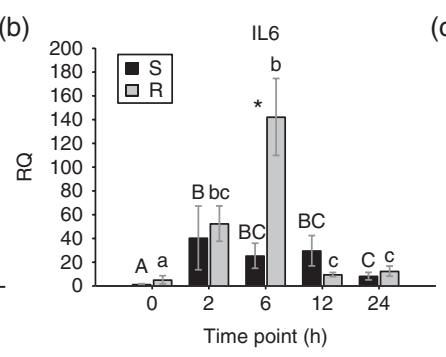

(f)

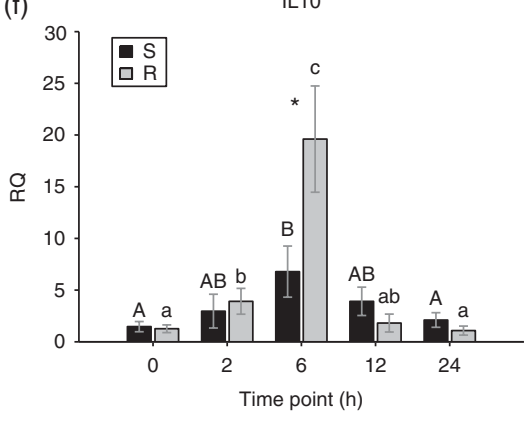

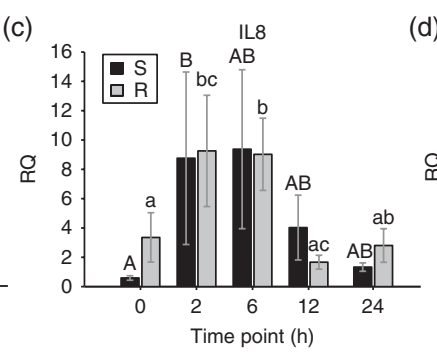

(d)

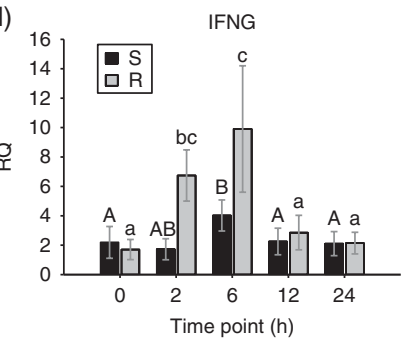

(g)

IL1RN

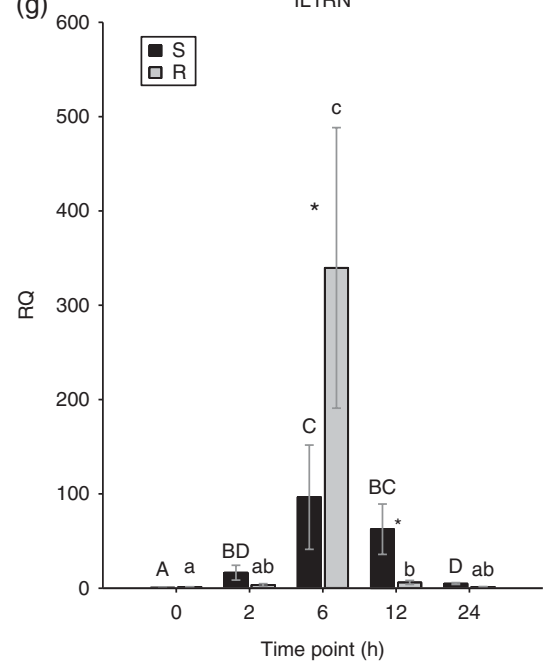

Figure 1 (a, b, c, d, e, f and g) Mean endometrial cytokine mRNA expression before (0) and 2, 6, 12, 24 h after insemination with killed spermatozoa in susceptible (S; dark bars) and resistant (R; light bars) mares. RQ values describe fold changes in each mare compared to the $\Delta C T$ value of resistant mares at $0 \mathrm{~h}$. Data presented in graphs are the raw RQ values, although data were log 10 or square root transformed for statistical analysis. Error bars report S.E.M. Comparisons were made within groups ( $\mathrm{S}$ or $\mathrm{R}$ ) at each time point and different letters over the bars (capital letters for susceptible; lowercase for resistant) within each group represent significant differences. Comparisons were also made between groups at each time point, and significant differences are represented by an asterisk (*). Significance set to $P<0.05$. 
expression at $2 \mathrm{~h}$ when compared with $24 \mathrm{~h}(P=0.033)$ and resistant mares had an increase at $6 \mathrm{~h}$ when compared with 12 and $24 \mathrm{~h}(P \leq 0.002)$. Resistant mares had a higher level of expression at $6 \mathrm{~h}$ when compared with susceptible mares $(P=0.01)$ (Fig. 1b).

IL8 mRNA expression in resistant mares was increased at 2 and $6 \mathrm{~h}$ after insemination $(P<0.04)$ followed by a decrease from 6 to $12 \mathrm{~h}(P=0.042)$. In susceptible mares, there was a significant rise in expression at $2 \mathrm{~h}$ after insemination $(P=0.005)$. There were no differences detected in expression between susceptible and resistant mares (Fig. 1c).

Interferon gamma (IFNG) mRNA expression in resistant mares was increased at 2 and $6 \mathrm{~h}$ after insemination $(P \leq 0.001)$. Susceptible mares had increased expression at $6 \mathrm{~h}$ compared with pre-insemination levels, 12 , and $24 \mathrm{~h}(P \leq 0.046)$. There were no differences between susceptible and resistant mares; however, the patterns of IFNG mRNA expression differed between the two groups shortly after insemination. Although both groups exhibited a response, the resistant mares had increased expression at $2 \mathrm{~h}$, whereas mRNA expression in the susceptible group did not increase until $6 \mathrm{~h}$ after insemination (Fig. 1d).

TNFA mRNA expression in susceptible mares did not differ at any time point. In resistant mares, there was an increase in expression at $2 \mathrm{~h}$ compared with the preinsemination, 12 , and $24 \mathrm{~h}$ time points $(P \leq 0.032)$. Expression decreased at $12 \mathrm{~h}$ from 2 to $6 \mathrm{~h}(P \leq 0.034)$, and at $24 \mathrm{~h}$, was lower than pre-insemination levels $(P=0.046)$. There were no differences between groups (Fig. 1e).

IL10 mRNA expression in resistant mares was upregulated at $6 \mathrm{~h}$ compared with all time points $(P \leq 0.001)$, and at $2 \mathrm{~h}$ compared with pre-insemination levels and $24 \mathrm{~h}(P \leq 0.045)$. Susceptible mares showed an increase at $6 \mathrm{~h}$ compared with pre-insemination levels and $24 \mathrm{~h}$ $(P \leq 0.027)$. Resistant mares had higher expression than susceptible mares at $6 \mathrm{~h}(P=0.021)$ (Fig. 1f).

ILIRN mRNA expression peaked at $6 \mathrm{~h}$ in resistant mares $(P<0.001)$, with a marked increase from 2 to $6 \mathrm{~h}$ $(P<0.001)$ and a decrease from 6 to $12 \mathrm{~h}(P<0.001)$. Expression returned to pre-insemination levels by $24 \mathrm{~h}$. Susceptible mares had increased expression at all time points after insemination $(P \leq 0.017)$, with the highest levels observed at 6 and $12 \mathrm{~h}$. Resistant mares had higher mRNA expression at $6 \mathrm{~h}$ than susceptible mares $(P=0.013)$, and susceptible mares had higher expression at $12 \mathrm{~h}$ than resistant mares $(P=0.017)$ (Fig. $1 \mathrm{~g}$ ).

The mRNA expression patterns for the pro-inflammatory cytokines IL $1 B, I L 8$, IFNG, and TNFA were similar in both groups of mares, with an initial increase at 2 and $6 \mathrm{~h}$, followed by a decrease toward pre-insemination levels. Although there were no differences between susceptible and resistant mares at any time point for these cytokines, there were subtle variations in the rise toward the peak and the return to pre-insemination level expression. All mares returned to pre-insemination levels of mRNA expression of ILIB and IL 8 by $12 \mathrm{~h}$. However, resistant mares had a significant decrease in expression from 6 to $12 \mathrm{~h}$, while the susceptible mares had a less rapid decline in expression to pre-insemination levels compared with the resistant mares.

There were distinct differences in the patterns of expression between resistant and susceptible mares for $I L 6$ and the inflammatory modulating cytokines ILIRN and IL10. mRNA expression for all three cytokines was decreased in the susceptible mares at $6 \mathrm{~h}$ when compared with the resistant mares, and susceptible mares had a higher expression of $I L 1 R N$ at $12 \mathrm{~h}$ when compared with the resistant mares. An outline connecting the mean expression at each time point for the three cytokines shows that the resistant mares have an expression profile with a sharp peak at $6 \mathrm{~h}$, while the lines for the susceptible mares resemble more of a hump, with slower increases to and decreases from the peak.

\section{Endometrial inflammatory cells}

Susceptible mares had an increase in the number of PMNs in the endometrial tissue at all time points after breeding $(P \leq 0.012)$ (Fig. 2). There were no significant increases in PMN infiltration at any time point for the resistant mares; however, it should be noted that there was a tendency for an increase $6 \mathrm{~h}$ after breeding compared with the pre-insemination $(P=0.054)$ and 2 $(P=0.056) \mathrm{h}$ time points (Fig. 2). Susceptible mares had a higher infiltration of PMNs $2 \quad(P=0.010)$ and 12 $(P=0.031) \mathrm{h}$ after breeding compared with resistant mares (Fig. 2).

\section{Discussion}

Pro-inflammatory cytokines initiate inflammation, and once produced, a cascade of inflammatory events occurs (Kuby 1992, Parham 2005). A timely response to pathogens is important for an effective resolution of inflammation and preservation of tissue, and IFNG is important in the initiation of inflammation (Schroder et al. 2004). The delayed rise in IFNG mRNA in the susceptible mares observed in this study may reflect a delayed inflammatory response to spermatozoa compared with resistant mares. Furthermore, the differences observed in the mRNA expression patterns of the pro-inflammatory cytokines suggest that susceptible mares have a slower return to pre-insemination levels, possibly contributing to the prolonged clinical signs observed in the clinical setting (Zent et al. 1998).

As with the other pro-inflammatory cytokines, mRNA expression for IL6 increased in response to challenge in both groups. IL6 was the only pro-inflammatory cytokine with a significant difference between the two groups, with resistant mares having increased mRNA expression compared with susceptible mares at $6 \mathrm{~h}$ (which is similar 


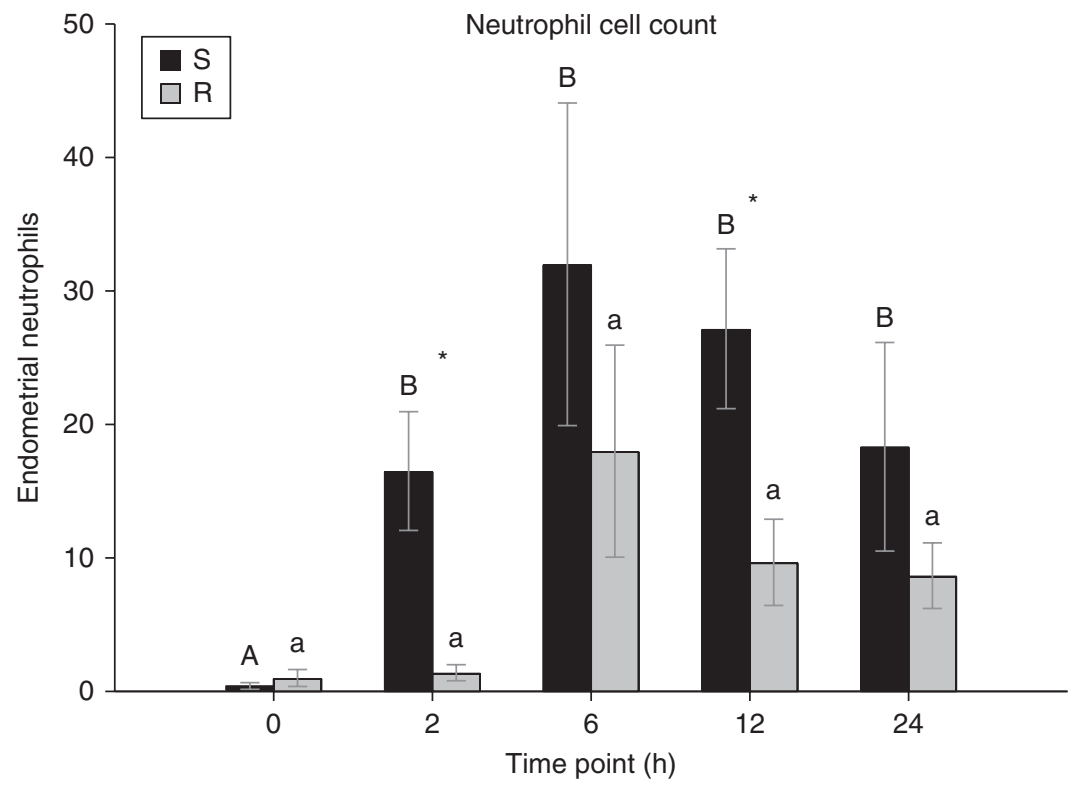

Figure 2 Mean endometrial PMN infiltration before (0) and 2, 6, 12, and $24 \mathrm{~h}$ after insemination with killed spermatozoa in susceptible (S; dark bars) and resistant ( $\mathrm{R}$; light bars) mares. Error bars report S.E.M. Comparisons were made within groups ( $\mathrm{S}$ or $\mathrm{R}$ ) at each time point and different letters over the bars (capital letters for susceptible; lowercase for resistant) within each group represent significant differences. Comparisons were also made between groups at each time point, and significant differences are represented by an asterisk $(*)$. Significance set to $P<0.05$. to the findings of the inflammatory modulating cytokines $I L 10$ and ILIRN). While IL6 is considered a proinflammatory cytokine, it has protective roles in early acute inflammation and shock through the modulation of other pro-inflammatory cytokines (Barton \& Jackson 1993, Xing et al. 1998, Diao \& Kohanawa 2005) and the induction of inflammatory modulating cytokines, such as ILIRN (Tilg et al. 1994). In addition to the resolution of acute inflammation, IL6 and its receptor has been suggested to have implications in the transition from innate to acquired immunity and the persistence of chronic inflammation (Kishimoto et al. 1995, Atreya et al. 2000, Jones 2005). It is possible that the increase in IL6 mRNA 6 h after insemination in resistant mares compared with susceptible mares may reflect initial inflammatory modulating roles of IL6 (similar to those of IL10 and $I L 1 R N$ ) during this time (Tilg et al. 1994). Treatment with the anti-inflammatory dexamethasone in susceptible mares has been demonstrated to increase endometrial IL6 mRNA expression $3 \mathrm{~h}$ after inoculation with $E$. coli when compared with susceptible mares inoculated without dexamethasone treatment (Christoffersen et al. 2012a). The same group observed an increase in mRNA expression of the immune modulating cytokine IL 10 and a decrease in the pro-inflammatory cytokine $I L 1 B 3 \mathrm{~h}$ after treatment. These findings further support the idea that IL6 may be initially involved with an immune modulating response to challenge, as the initial mRNA response of IL6 to dexamethasone and E. coli was similar to that of the anti-inflammatory $I L 10$ and opposite to that of the pro-inflammatory $I L 1 B$. In addition, the elevated levels of IL6 mRNA observed in untreated susceptible mares inoculated with E. coli at $72 \mathrm{~h}$ is similar to the mRNA response of the $I L 1 B$ and opposite to IL10 (Christoffersen et al. 2012b), which may reflect the pro-inflammatory actions of IL6 associated with inflammation more persistent in nature.

There is a delicate balance between the pro- and anti-inflammatory response; pro-inflammatory cytokines act to initiate and increase the response, while antiinflammatory cytokines modulate the pro-inflammatory cytokines (Parham 2005, Hackett et al. 2008). IL10 is essential for the modulation of the immune response, and deficiencies in IL10 can lead to tissue damage (Cyktor \& Turner 2011). In addition, the IL1 system is involved with both pathologic states as well as normal reproductive function (Takehara et al. 1994, Van der Hoek et al. 1998, Martoriati et al. 2003, Gerard et al. 2004). ILIRN mediates ILI, which, if overactive, can damage tissue (Gerard et al. 2004). In this study, susceptible mares had a less defined immune modulating response than resistant mares, suggesting that these mares were less able to respond to and initiate the modulation of inflammation.

The cytokine cascade initiates inflammatory cell recruitment, and it is possible that an increase in cytokine expression could be related to the increase in endometrial PMNs observed in this study. The findings that PMN counts in this study were observed to be highest $6 \mathrm{~h}$ after breeding in susceptible mares are consistent with in vitro and in vivo studies that found that PMN migration peaked $6 \mathrm{~h}$ after IL8 induction (Zerbe et al. 2003). Interestingly, in this study, susceptible mares had an increase in IL 8 mRNA $2 \mathrm{~h}$ after breeding, whereas resistant mares had an increase at both 2 and $6 \mathrm{~h}$ after breeding. However, the resistant mares had no significant increase in endometrial PMN infiltration, while the susceptible mares had increases in endometrial $\mathrm{PMN}$ at all time points compared with pre-insemination counts. It is unclear why IL 8 mRNA expression did not 
directly correlate with PMN infiltration. A possible explanation is that resistant mares have a differential posttranscriptional regulation of IL8 compared with susceptible mares. Also, the migration of PMNs to the uterine lumen may be hindered in the susceptible mares because the endometria of susceptible mares have more degenerative changes, and PMNs may have trouble moving through the fibrotic endometrial tissue. In addition, the uterine contractions in response to inflammation may aid in the movement of PMNs into the uterine lumen, and the migration of the PMNs may be slower in susceptible mares, as they have reduced myometrial activity (Troedsson et al. 1993a, LeBlanc et al. 1994). The increase in endometrial PMNs in susceptible mares may reflect longer persistence of PMN accumulation rather than differences in cellular responses and may be more a symptom than cause of prolonged inflammation. These explanations are speculative and warrant further investigation. An increase in $\mathrm{PMNs}$ or other inflammatory cells is reflective of an inflammatory response, and regardless of the source of cytokines, the differences in cytokine expression observed between the two groups of mares illustrate differences occurring on an mRNA level during the resolution of inflammation.

These data support previous research that illustrated a local immune response in response to intrauterine challenge with dead spermatozoa (Fumuso et al. 2007), and the conclusions that susceptible mares are less capable of clearing the uterine inflammation than resistant mares (Hughes \& Loy 1969, Troedsson et al. 1993b, Fumuso et al. 2006, Woodward et al. 2012). However, the results conflict with those from other studies as to which cytokines differ and at which time points (Fumuso et al. 2003, 2006). A possible explanation for discrepancies between studies is the criteria by which mares are selected as resistant vs susceptible to PBIE. It is important to determine that mares are free of inflammation before breeding (via uterine culture and cytology) because chronic inflammation may shift cytokine mRNA profiles before insemination, therefore altering results whether data are to be analyzed using a relative quantification method (as may have been the case in the later studies). A critical factor for classification of mares is to ensure that the criteria for susceptibility and resistance are stringent enough to represent the truly resistant or susceptible mare, as many mares fall into an intermediate category. The model used in this experiment uses such strict criteria and therefore is appropriate for the study of PBIE. In addition, these data demonstrate that the time point of $24 \mathrm{~h}$ may be too late to see a response with some cytokines in normal mares, which could explain inconsistencies with this experiment and previously published works (Fumuso et al. 2006, Nash et al. 2010). For example, if normal mares are meant to resolve inflammation within $48 \mathrm{~h}$, it is plausible that at $24 \mathrm{~h}$ after challenge, neutrophils are no longer being actively recruited, and although neutrophils are likely to still be present in the uterus (Nash et al. 2010), IL8 may not be produced at elevated levels during this time.

The findings that susceptible mares have an altered initial inflammatory response on a gene expression level support other data describing differences in the ability to clear inflammation between resistant and susceptible mares after bacterial challenge (Troedsson \& Liu 1991, Troedsson et al. 1993a, LeBlanc et al. 1994). Although the clinical signs differentiating resistant and susceptible mares are observed several days after insemination, to better define the pathogenesis of PBIE it is important to elucidate the timing of the uterine immune response of the resistant mare compared to the susceptible mare at a molecular level. It is possible that the actual peaks of cytokine expression may fall at a time point other than the ones observed in this study. However, when considering the five time points investigated, our data suggest that around $6 \mathrm{~h}$ after insemination may be a critical time in developing susceptibility, as this time point was both the peak of expression observed in this study for many of the cytokines and the time point at which susceptible and resistant mares differed in their mRNA expression of IL6, IL10, and ILIRN. Furthermore, a failure to resolve breeding-induced inflammation in a timely fashion may be due in part to a failure to mobilize inflammatory (both pro- and anti-inflammatory) cytokines during the early inflammatory period, which could contribute to a delayed resolution of inflammation in susceptible mares.

It is unknown whether there was an effect of stallion on inflammatory response. Spermatozoa have been shown to be the component in the ejaculate that causes inflammation, with seminal plasma modulating the response (Troedsson et al. 2005, Fiala et al. 2007). To account for any differences between the protein composition of the seminal plasma or viability counts between stallions, the seminal plasma was removed and all spermatozoa were killed before insemination. In conclusion, the results from this study suggest that around $6 \mathrm{~h}$ after insemination may be a critical time in the establishment of the mechanism for uterine response and clearance. It is possible that the altered local cytokine response observed in susceptible mares could lead to an impaired ability to clear inflammation, as the cytokine response to inflammation is the first step in recognition and removal of foreign material. With an increased understanding of the cytokine pathways shortly after breeding, research can continue in elucidating the mechanisms in later stages of inflammation, and eventually, treatment strategies can be improved upon.

\section{Materials and Methods}

\section{Animals}

Ninety-two mares (Equus caballus) of mixed breeds, age (2-27 years old), and foaling history were kept on pasture 
supplemented with grain and hay and were provided with water and salt ad libitum. Three stallions were maintained under similar housing conditions to that of the mares. The experiment was approved by the University of Kentucky's Institutional Animal Care and Use Committee (protocol numbers 2009-0455 and 2009-0602).

\section{Preparation of sperm for insemination}

Semen was regularly collected from the stallions and used as needed throughout the experiment. Freeze-killed spermatozoa were prepared by removing the seminal plasma from ejaculates using centrifugation (2000 $\mathrm{g}$ for $10 \mathrm{~min}$ ), and resuspending the spermatozoa pellet in milk-based extender (EquiPro, Minitube, Verona, WI, USA) in aliquots of $1 \times 10^{9}$ spermatozoa in $30 \mathrm{ml}$ extender followed by at least two freeze $\left(-20{ }^{\circ} \mathrm{C}\right) /$ thaw cycles of the aliquots to kill the spermatozoa.

\section{General experimental procedure for the selection of mares}

Mares were examined for susceptibility to PBIE based on endometrial histology and the results of a spermatozoa challenge as described previously (Woodward et al. 2012). Endometrial biopsies $(\sim 300 \mathrm{mg}$ of tissue $)$ were obtained during diestrus using an alligator jaw biopsy instrument, fixed in $10 \%$ formalin, sectioned at $5 \mu \mathrm{m}$, and stained with hematoxylin and eosin. Each biopsy was examined for periglandular fibrosis, inflammatory cells, glandular distribution, and lymphatic lacunae and then graded according to Kenney \& Doig (1986). Mares with scores of I or IIA were considered potentially resistant to PBIE $(n=27)$, while those with scores of IIB or III were potentially susceptible to PBIE $(n=65)$ (Troedsson et al. 1993b, Woodward et al. 2012).

After selection as potentially resistant or susceptible to PBIE, the mares' reproductive tracts were observed regularly for signs of estrus and pending ovulation using transrectal ultrasonography. Estrus was defined by the presence of uterine edema, a relaxed cervix, and at least one follicle $35 \mathrm{~mm}$ or larger in diameter in the absence of a corpus luteum. Once estrus was detected, mares were evaluated for the presence of intrauterine inflammatory cells using a cytobrush (Minitube) or low-volume lavage to obtain samples and for intrauterine bacteria using a double-guarded swab (Minitube) to obtain samples and then were subsequently inseminated with freeze-killed spermatozoa (prepared as earlier). For the cytological evaluations, a sample positive for inflammation was defined as more than two neutrophils per five fields at $\times 400$ magnification. Swab samples were cultured on blood agar, then incubated at $37{ }^{\circ} \mathrm{C}$ for $24 \mathrm{~h}$, and evaluated for bacterial growth. Mares were challenged with an i.u. inoculation of $1 \times 10^{9}$ freeze-killed stallion spermatozoa in $30 \mathrm{ml}$ of milk-based semen extender (Minitube). Only mares with negative cytology and no bacterial growth before insemination were considered for the experiment.

Potentially susceptible mares were evaluated $96 \mathrm{~h}$ after insemination and were confirmed as susceptible if they had i) positive cytology and ii) uterine fluid retention. Potentially resistant mares were assessed $48 \mathrm{~h}$ after breeding, and those with i) negative cytology and culture in addition to ii) no uterine fluid retention were confirmed as resistant mares (Troedsson \& Liu 1991, Alghamdi et al. 2005). All mares not meeting the criteria for classification as susceptible or resistant were considered as intermediate and excluded from the study. From the herd of 92 mares, a total of six susceptible and six resistant mares were identified and used in this study.

\section{Treatments}

Over five subsequent cycles, estrus was induced after day 5 of diestrus by i.m. administration of prostaglandin F2 $\alpha$ (Lutalyse 7.5 mg, Pfizer, New York, NY, USA). Once estrus was detected, mares were evaluated for cytological and bacterial findings (as described earlier) and subsequently inseminated with $1 \times 10^{9}$ dead spermatozoa (as described earlier). Only estrous cycles with negative cytology and culture were used for the experiment; if mares were positive for cytology or culture at the time of insemination, they were treated and inseminated again during the following cycle (this happened four times throughout the experiment).

Two uterine biopsies were collected at one time point per cycle in randomized order. Time points were 0 (before insemination), 2, 6, 12, and $24 \mathrm{~h}$ after insemination. The tissue from the first biopsy was either snap frozen in liquid nitrogen and stored at $-80^{\circ} \mathrm{C}$ until further processing or stored in RNAlater (Applied Biosystems) overnight at $4{ }^{\circ} \mathrm{C}$, then moved to $-20{ }^{\circ} \mathrm{C}$ for storage until further processing. Tissue from the second biopsy was fixed in $10 \%$ formalin for staining and observation of inflammatory cells.

\section{qPCR analysis}

Total RNA was extracted using TRIzol reagent (Invitrogen), precipitated using sodium acetate and isopropanol, resuspended

Table 1 Dual hydrolysis primer/probe set sequences for the detection of equine mRNA. Primer/probe sets were designed using Assays-By-Design (Applied Biosystems).

\begin{tabular}{llll}
\hline Cytokine & Forward primer sequence & Reverse primer sequence & Probe sequence \\
\hline EqACTB & CTGGACTTCGAGCAGGAGATG & CGTCGGGCAGCTCGTA & CCGCGGCCTCCAGCT \\
EqIL1B & CCGACACCAGTGACATGATGA & ATCCTCCTCAAAGAACAGGTCATTC & ATTGCCGCTGCAGTAAG \\
EqIL6 & GGATGCTTCCAATCTGGGTTCAAT & TCCGAAAGACCAGTGGTGATTTT & ATCAGGCAGGTCTCCTG \\
EqIL8 & GCCGTCTTCCTGCTTTCTG & CCGAAGCTCTGCAGTAATTCTTGAT & CAACCGCAGCTTCAC \\
EqINFG & AGCAGCACCAGCAAGCT & TTTGCGCTGGACCTTCAGA & ATTGAGATTCCGGTAAATG \\
EqTNF & TTACCGAATGCCTTCCAGTCAAT & GGGCTACAGGCTTGTCACTT & CCAGACACTCAGATCAT \\
EqIL10 & ATGCCCCAGGCTGAGAAC & CGGAGGGTCTTCAGCTTTTCC & CCAGACATCAAGGAGCACG \\
EqIL1RN & AGTTGCTGGATACTTGCAAGAATCA & GAGTCCCAGGAATAGAGCATCAG & CATCTATCTTCTCTTGTAATTTA \\
\hline
\end{tabular}


in $\mathrm{ddH}_{2} \mathrm{O}$, and DNAse treated with a commercially available kit (DNA-free, Applied Biosystems) and then analyzed for quality and quantity using a NanoDrop spectrophotometer (Thermo Scientific, Wilmington, DE, USA). The ranges for the $260 / 280$ and $260 / 230$ ratios were $1.92-2.2$ and $1.89-2.4$ respectively. RNA $(1.5 \mu \mathrm{g})$ in $41.5 \mu \mathrm{l} \mathrm{ddH}_{2} \mathrm{O}$ was reverse transcribed in a reaction using AMV Reverse transcriptase $(0.5 \mu \mathrm{l} ; 10 \mathrm{U} / \mu \mathrm{l}), 5 \times \mathrm{RT}$ buffer $(16 \mu \mathrm{l})$, RNAsin $(1 \mu \mathrm{l} ; 40 \mathrm{U} / \mu \mathrm{l})$, $\mathrm{MgCl}(16 \mu \mathrm{l} ; 25 \mathrm{mM}), \mathrm{dNTP}(4 \mu \mathrm{l} ; 10 \mathrm{mM})$, and Oligo(dT) primer $(1 \mu \mathrm{l} ; 500 \mu \mathrm{g} / \mathrm{ml})$ (all reagents from Promega). Samples were incubated at $42{ }^{\circ} \mathrm{C}$ for $60 \mathrm{~min}$ and then $95^{\circ} \mathrm{C}$ for $5 \mathrm{~min}$. cDNA was diluted 1:1 with $\mathrm{dd}_{2} \mathrm{O}$, and qPCR for each sample was performed using $4.5 \mu \mathrm{l}$ cDNA, $5 \mu$ Sensimix II (Bioline, Tauton, MA, USA), and $0.5 \mu \mathrm{l}$ of a custom dual hydrolysis primer/probe set (Applied Biosystems; Table 1). Reactions were performed in duplicate, and using the $7900 \mathrm{HT}$ Fast Real-Time PCR System (Applied Biosystems), were incubated at $95{ }^{\circ} \mathrm{C}$ for $10 \mathrm{~min}$, followed by 45 cycles of $95{ }^{\circ} \mathrm{C}$ for $15 \mathrm{~s}$ and $60{ }^{\circ} \mathrm{C}$ for $60 \mathrm{~s}$. PCR efficiencies were calculated using LinRegPCR (version 7.0). $\beta$-Actin (ACTB) was used as the reference gene, as it was previously determined to be the most stably expressed gene out a panel of four reference genes (18S RNA, $\beta$-glucuronidase, glyceraldehydes 3-phosphate dehydrogenase, and ACTB) (Christoffersen et al. 2010). Results are expressed as mean relative quantification values (RQ) that were calculated using the $2^{-\Delta \Delta C T}$ method (Livak \& Schmittgen 2001), with the calibrator as the mean cycle threshold $(\Delta C \mathrm{~T})$ value of the $0 \mathrm{~h}$ collections from the resistant mares.

\section{Inflammatory cell count}

Biopsies were fixed in 10\% formalin, sectioned, and stained with hematoxylin and eosin. For each sample, a blinded researcher counted PMNs and lymphocytes from five fields at $\times 400$ magnification and an average number of inflammatory cells per sample were recorded.

\section{Statistical analysis}

Data were analyzed using SigmaStat $\subset$ (Systat Software, Inc., Chicago, IL, USA) with two-way repeated measures ANOVA tests. Data were log10 or square root transformed for normal distribution, and outliers were defined as \pm 2 s.D. from the mean and were removed from statistical analyses (five of 406 data points removed). Missing data points were automatically calculated by the software using a general linear model (Sigma Stat User Guide, p. 379). Comparisons were made between groups at each time point and between time points within groups. Post hoc analysis was performed using the Holm-Sidak method, and significance was set to $P<0.05$.

\section{Declaration of interest}

The authors declare that there is no conflict of interest that could be perceived as prejudicing the impartiality of the research reported.

\section{Funding}

The work was supported by funds from the Gluck Fellowship in the Department of Veterinary Science and the Janet $\mathrm{H}$ Koller Endowment for Equine Research (grant number 1215389420).

\section{Acknowledgements}

The authors would like to thank Mr Lynn Ennis, Mr Kevin Gallagher, and the University of Kentucky's Maine Chance Farm for the management and care of the horses, the University of Kentucky Veterinary Diagnostic Laboratory for the use of their equipment and sample processing, Dr Gabriel Davolli and Ms Pauline Peugnet for their technical assistance, and Dr J S Butler for his help with the experimental design and statistical analysis.

\section{References}

Adams GP, Kastelic JP, Bergfelt DR \& Ginther OJ 1987 Effect of uterine inflammation and ultrasonically detected uterine pathology on fertility in the mare. Journal of Reproduction and Fertility. Supplement 35 445-454.

Alghamdi AS, Foster DN, Carlson CS \& Troedsson MH 2005 Nitric oxide levels and nitric oxide synthase expression in uterine samples from mares susceptible and resistant to persistent breeding-induced endometritis. American Journal of Reproductive Immunology 53 230-237. (doi:10.1111/j.1600-0897.2005.00270.x)

Atreya R, Mudter J, Finotto S, Mullberg J, Jostock T, Wirtz S, Schutz M, Bartsch B, Holtmann M, Becker C et al. 2000 Blockade of interleukin 6 trans signaling suppresses T-cell resistance against apoptosis in chronic intestinal inflammation: evidence in Crohn disease and experimental colitis in vivo. Nature Medicine 6 583-588. (doi:10.1038/75068)

Barton BE \& Jackson JV 1993 Protective role of interleukin 6 in thelipopolysaccharide-galactosamine septic shock model. Infection and Immunity 61 1496-1499.

Betteridge KJ, Eaglesome MD, Mitchell D, Flood PF \& Beriault R 1982 Development of horse embryos up to twenty two days after ovulation: observations on fresh specimens. Journal of Anatomy 135 191-209.

Christoffersen M, Baagoe CD, Jacobsen S, Bojesen AM, Petersen MR \& Lehn-Jensen H 2010 Evaluation of the systemic acute phase response and endometrial gene expression of serum amyloid $A$ and pro- and antiinflammatory cytokines in mares with experimentally induced endometritis. Veterinary Immunology and Immunopathology 138 95-105. (doi:10.1016/j.vetimm.2010.07.011)

Christoffersen M, Woodward EM, Bojesen AM, Petersen MR, Squires EL, Lehn-Jensen H \& Troedsson MHT 2012a Effect of immunomodulatory therapy on the endometrial inflammatory response to induced infectious endometritis in susceptible mares. Theriogenology 78 991-1004. (doi:10.1016/j.theriogenology.2012.04.016)

Christoffersen M, Woodward EM, Bojesen AM, Petersen MR, Squires EL, Lehn-Jensen H \& Troedsson MHT 2012 $b$ Inflammatory responses to induced infectious endometritis in mares resistant or susceptible to persistent endometritis. BMC Veterinary Research 8 41. (doi:10.1186/ 1746-6148-8-41)

Cyktor JC \& Turner J 2011 Interleukin-10 and immunity against prokaryotic and eukaryotic intracellular pathogens. Infection and Immunity 79 2964-2973. (doi:10.1128/IAI.00047-11)

Diao H \& Kohanawa M 2005 Endogenous interleukin-6 plays a crucial protective role in streptococcal toxic shock syndrome via suppression of tumor necrosis factor $\alpha$ production. Infection and Immunity 73 3745-3748. (doi:10.1128/IAI.73.6.3745-3748.2005)

Fiala SM, Pimentel CA, Mattos ALG, Gregory RM \& Mattos RC 2007 Effect of sperm numbers and concentration on sperm transport and uterine inflammatory response in the mare. Theriogenology 67 556-562. (doi:10.1016/j.theriogenology.2006.09.005) 
Freeman DA, Weber JA, Geary RT \& Woods GL 1991 Time of embryo transport through the mare oviduct. Theriogenology 36 823-830. (doi:10.1016/0093-691X(91)90348-H)

Fumuso E, Giguere S, Wade J, Rogan D, Videla-Dorna I \& Bowden RA 2003 Endometrial IL-1 $\beta$, IL- 6 and TNF- $\alpha$, mRNA expression in mares resistant or susceptible to post-breeding endometritis. Effects of estrous cycle, artificial insemination and immunomodulation. Veterinary Immunology and Immunopathology 96 31-41. (doi:10.1016/S01652427(03)00137-5)

Fumuso E, Aguilar G, Giguere S, David O, Wade J \& Rogan D 2006 Interleukin-8 (IL-8) and 10 (IL-10) mRNA transcriptions in the endometrium of normal mares and mares susceptible to persistent post-breeding endometritis. Animal Reproduction Science 94 282-285. (doi:10.1016/j.anireprosci.2006.04.006)

Fumuso EA, Aguilar J, Giguere S, Rivulgo M, Wade J \& Rogan D 2007 Immune parameters in mares resistant and susceptible to persistent post-breeding endometritis: effects of immunomodulation. Veterinary Immunology and Immunopathology 118 30-39. (doi:10.1016/j.vetimm. 2007.04.009)

Gerard N, Caillaud M, Martoriati A, Goudet G \& Lalmanach AC 2004 The interleukin-1 system and female reproduction. Journal of Endocrinology 180 203-212. (doi:10.1677/joe.0.1800203)

Hackett TL, Holloway R, Holgate ST \& Warner JA 2008 Dynamics of proinflammatory and anti-inflammatory cytokine release during acute inflammation in chronic obstructive pulmonary disease: an ex vivo study. Respiratory Research 9 47. (doi:10.1186/1465-9921-9-47)

Hill J \& Gilbert R 2008 Reduced quality of bovine embryos cultured in media conditioned by exposure to an inflamed endometrium. Australian Veterinary Journal 86 312-316. (doi:10.1111/j.1751-0813. 2008.00326.x)

Hughes J \& Loy RG 1969 Investigation on the effect of intrauterine inoculations of streptococcus zooepidemicus in the mare. Proceedings of the American Association of Equine Practitioners 15 289-292.

Jones SA 2005 Directing transition from innate to acquired immunity: defining a role for IL-6. Journal of Immunology 175 3463-3468.

Kenney RM \& Doig PA 1986 Equine endometrial biopsy. In Current Therapy in Theriogenology: Diagnosis, Treatment, and Prevention of Reproductive Diseases in Small and Large Animals, 2nd edn, pp 723-729. Ed D Marrow. Philadelphia: WB Saunders.

Kishimoto T, Akira S, Narazaki M \& Taga T 1995 Interleukin-6 family of cytokines and gp130. Blood 86 1243-1254.

Kuby J 1992 Immunology. New York: WH Freeman and Company.

LeBlanc MM, Neuwirth L, Asbury AC, Tran T, Mauragis D \& Klapstein E 1994 Scintigraphic measurement of uterine clearance in normal mares and mares with recurrent endometritis. Equine Veterinary Journal 26 109-113. (doi:10.1111/j.2042-3306.1994.tb04346.x)

Livak KJ \& Schmittgen TD 2001 Analysis of relative gene expression data using real-time quantitative PCR and the $2(-$ Delta Delta $C(\mathrm{~T}))$ method. Methods 25 402-408. (doi:10.1006/meth.2001.1262)

Martoriati A, Duchamp G \& Gerard N 2003 In vivo effect of epidermal growth factor, interleukin-1 $\beta$, and interleukin-1RA on equine preovulatory follicles. Biology of Reproduction 68 1748-1754. (doi:10.1095/ biolreprod.102.012138)

Nash DM, Sheldon IM, Herath S \& Lane EA 2010 Markers of the uterine innate immune response of the mare. Animal Reproduction Science 119 31-39. (doi:10.1016/j.anireprosci.2009.11.008)

Oguri N \& Tsutsumi Y 1972 Non-surgical recovery of equine eggs, and an attempt at non-surgical egg transfer in horses. Journal of Reproduction and Fertility 31 187-195. (doi:10.1530/jrf.0.0310187)

Parham P 2005 The Immune System. New York: Garland Science.
Reilas T, Huhtinen M, Oksanen M \& Katila T 2000 Relationship between embryo recovery rate and uterine lavage fluid composition in post partum mares. Reproduction, Nutrition, and Development 40 383-391. (doi:10.1051/rnd:2000106)

Schroder K, Hertzog PJ, Ravasi T \& Hume DA 2004 Interferon-gamma: an overview of signals, mechanisms and functions. Journal of Leukocyte Biology 75 163-189. (doi:10.1189/jlb.0603252)

Takehara Y, Dharmarajan AM, Kaufman G \& Wallach EE 1994 Effect of interleukin-1 $\beta$ on ovulation in the in vitro perfused rabbit ovary. Endocrinology 134 1788-1793. (doi:10.1210/en.134.4.1788)

Tilg H, Trehu E, Atkins MB, Dinarello CA \& Mier JW 1994 Interleukin-6 (IL-6) as an anti-inflammatory cytokine: induction of circulating IL-1 receptor antagonist and soluble tumor necrosis factor receptor p55. Blood 83 113-118.

Traub-Dargatz JL, Salman MD \& Voss JL 1991 Medical problems of adult horses, as ranked by equine practitioners. Journal of the American Veterinary Research 198 1745-1747.

Troedsson MH \& Liu IK 1991 Uterine clearance of non-antigenic markers $(51 \mathrm{Cr})$ in response to a bacterial challenge in mares potentially susceptible and resistant to chronic uterine infections. Journal of Reproduction and Fertility. Supplement 44 283-288.

Troedsson MH, Liu IK, Ing M, Pascoe J \& Thurmond M 1993a Multiple site electromyography recordings of uterine activity following an intrauterine bacterial challenge in mares susceptible and resistant to chronic uterine infection. Journal of Reproduction and Fertility 99 307-313. (doi:10.1530/jrf.0.0990307)

Troedsson MH, deMoraes MJ \& Liu IK 1993b Correlations between histologic endometrial lesions in mares and clinical response to intrauterine exposure with Streptococcus zooepidemicus. American Journal of Veterinary Research $\mathbf{5 4}$ 570-572.

Troedsson MHT, Desvousges A, Alghamdi AS, Dahms B, Dow CA, Hayna J, Valesco R, Collahan PT, Macpherson ML, Pozor M et al. 2005 Components in seminal plasma regulating sperm transport and elimination. Animal Reproduction Science 89 171-186. (doi:10.1016/ j.anireprosci.2005.07.005)

Van der Hoek KH, Woodhouse CM, Brannstrom M \& Norman RJ 1998 Effects of interleukin (IL)- 6 on luteinizing hormone- and IL-1 $\beta$-induced ovulation and steroidogenesis in the rat ovary. Biology of Reproduction 58 1266-1271. (doi:10.1095/biolreprod58.5.1266)

Woodward EM, Christoffersen M, Campos JR, Squires EL \& Troedsson MHT 2012 Susceptibility to persistent breeding-induced endometritis in the mare: relationship to endometrial biopsy score and age, and variations between seasons. Theriogenology 78 469-702. (doi:10.1016/j.theriogenology.2012.02.028)

Xing Z, Gauldie J, Cox G, Baumann H, Jordana M, Lei XF \& Achong MK 1998 IL-6 is an antiinflammatory cytokine required for controlling local or systemic acute inflammatory responses. Journal of Clinical Investigation 101 311-320. (doi:10.1172/JCI1368)

Zent W, Troedsson M \& Xue JL 1998 Postbreeding uterine fluid accumulation in a normal population of Thoroughbred mares: a field study. Proceedings of the American Association of Equine Practitioners 44 64-65.

Zerbe H, Schuberth HJ, Engelke F, Frank J, Klug E \& Leibold W 2003 Development and comparison of in vivo and in vitro models for endometritis in cows and mares. Theriogenology 60 209-223. (doi:10.1016/S0093-691X(02)01376-6)

Received 9 November 2012

First decision 10 December 2012

Accepted 16 January 2013 